Revista Internacional Educon | ISSN 2675-672

Volume 2, n. 1, e21021003, jan./abr. 2021

https://doi.org/10.47764/e21021003

\title{
Relação Professor e Estudante na Universidade: Visão de Acadêmicos do Curso de Letras
}

Professor-Student Relationship at University: The View of Academics

from Portuguese Vernacular Letters degree

Relación Profesor y Estudiante en la Universidad: Visión de Académicos

del Curso de Letras

MARINALVA LOPES RIBEIRO ${ }^{1}$, JEIZIANE DA SILVA OLIVEIRA ${ }^{2}$, E. MAURÍCIO DE OLIVEIRA RAMOS 3

${ }^{1}$ Universidade Estadual de Feira de Santana

${ }^{2}$ Universidade Estadual de Feira de Santana

${ }^{3}$ Universidade Estadual de Feira de Santana

\begin{abstract}
RESUMO: A relação estabelecida entre professores e estudantes pode favorecer ou dificultar, o processo de ensinoaprendizagem. Espera-se que, além do conbecimento teórico, o professor tenha atenção às culturas e identidades, expectativas e necessidades discentes e que desenvolva estratégias didáticas com vistas à aprendiragem significativa de tais sujeitos. O estudo éparte de uma pesquisa qualitativa, cujo objetivo foi conhecer as características das relacões instituidas entre docentes e discentes do curso de Letras Vernáculas de uma universidade pública. Os dados foram produzidos a partir de entrevista semiestruturada aplicada a acadêmicos do referido curso. Concluimos que os universitários valorizam o diálogo e a empatia, sentem falta da proximidade e da atenção dos docentes à suas necessidades pedagógicas. Relatam posturas docentes que dificultam aprendizados significativos.
\end{abstract}

\section{AFETIVIDADE. ENSINO SUPERIOR. RELAÇÃO DIALÓGICA. RELAÇÃO PROFESSOR-ESTUDANTE.}

\begin{abstract}
The relationship established between professors and students can favor, or hinder, the teachinglearning process. It is expected that, in addition to theoretical knowledge, the professor should pay attention to the different cultures and identities, expectations and needs of the students. Also, he should develop didactic strategies for their significative learning. This study is part of a qualitative research, whose objective was to know the characteristics of the relations established between professors and students of the Portuguese Vernacular Letters course at a public university. The data was produced from a semi-structured interview which was applied to academics of that course. We have concluded that university students value dialogue and empathy, and miss the proximity and attention from professors to their pedagogical needs. They report teaching positions that hinder significant learning.

\section{AFFECTIVITY. DIALOGIC RELATIONSHIP. PROFESSOR-STUDENT RELATIONSHIP. UNIVERSITY EDUCATION.}

Os autores cedem à Revista Internacional Educon os direitos de primeira publicação do presente artigo. Aplicam-se os termos de uma licença CreativeCommons Atribuição 4.0 Internacional (CC BY 4.0), que permite o uso irrestrito, a distribuição e a reprodução em qualquer meio desde que a publicação original seja corretamente citada. 
RESUMEN: La relación que se establece entre profesores y alumnos puede favorecer o dificultar el proceso de enseñanza-aprendizaje. Se espera que, además de los conocimientos teóricos, el docente preste atención a las culturas e identidades, expectativas y necesidades de los estudiantes y desarrolle estrategias didácticas con miras al aprendizaje significativo de dichas materias. El estudio es parte de una investigación cualitativa, cuyo objetivo fue conocerlas características de las relaciones que se establecen entre docentes y estudiantes del curso de Letras Vernáculas en una universidad pública. Los datos fueron producidos a partir de una entrevista semiestructurada aplicada a académicos de ese curso. Concluimos que los estudiantes universitarios valoran el diálogo y la empatía, extrañan la cercanía y atención de los docentes a sus necesidades pedagógicas. Informan puestos de enseñanza que obstaculizan el aprendizaje significativo.

\section{AFECTIVIDAD. ENSEÑANZA SUPERIOR. RELACIÓN DIALÓGICA. RELACIÓN} PROFESOR-ALUMNO.

\section{Introdução}

A universidade possui como uma de suas funções a produção da ciência, o que envolve o exercício permanente da crítica, da problematização dos conhecimentos gerados e de seus resultados. Nesse processo, tendo em vista que é a partir da interação do indivíduo com o meio físico e social que o conhecimento se constitui, Ribeiro e Santos (2020), Almeida e Pimenta (2014) destacam a necessidade de relações entre os sujeitos e objetos do conhecimento, formando um só organismo.

Assim, o primeiro passo para que o indivíduo estabeleça uma consciência crítica está na observação da sua própria realidade e no exercício da reflexão sobre ela, a fim de transformá-la (Queiroz et al., 2014). Segundo Freire (1994), um ato comprometido envolve ação e reflexão sobre si mesmo e sobre o seu estar no mundo.

Diante desse cenário, o ensino superior exige dos docentes a renovação de suas práticas, o que implica novos modos de planejar e realizar o processo de ensino-aprendizagem (Almeida \& Pimenta, 2014), cabendo ao professor, além do desenvolvimento profissional, diagnosticar as necessidades e expectativas dos estudantes para buscar estratégias de ensino adequadas ao seu contexto, avaliando seu desempenho, e verificando a consecução dos objetivos estabelecidos (Queiroz et al., 2014; Oliskovic \& Dal Piva, 2012).

Destarte, o docente necessita dominar vários saberes, dentre eles o da didática, responsável pelas teorizações e fundamentações sobre a relação entre professores e estudantes em torno do conhecimento (Cruz, 2017).

Todavia, alguns professores mantêm sua atuação limitada ao ensino de conteúdos específicos, evitando a discussão e a formação de valores que vão constituir o cidadão (Souza, 2016). Além disso, para muitos estudantes, de acordo com Soares et al. (2016), o professor usa estratégias de ensino que não contemplam suas formas de aprendizado, o que pode resultar em dificuldades e desinteresse do discente em aprender o componente curricular.

Diante de tal contexto, nos questionamos: como se dá a relação entre professores e estudantes universitários e quais as interferências de tal relação nos sentimentos e na aprendizagem dos estudantes? Para responder tais questões, realizamos uma pesquisa, cujo objetivo foi: conhecer as relações que estudantes de Letras Vernáculas estabelecem com seus professores. Alguns resultados dessa pesquisa serão apresentados neste trabalho que está dividido em 05 partes: introdução, metodologia, resultados e discussão, conclusões e as referências. 


\section{Metodologia}

Este estudo tem delineamento qualitativo, o qual, segundo Augusto et al. (2013), estimula a descrição detalhada dos fenômenos e dos elementos que o envolvem, e sua fonte de dados é o ambiente natural. Pensando na integridade dos participantes e para garantir a realização dentro dos padrões éticos de pesquisa com seres humanos, o projeto foi aprovado pelo Comitê de Ética em Pesquisa, parecer número 019859 \2019. Além disso, para manter sigilo quanto à identidade dos estudantes, usamos os códigos E1 e E2.

Realizamos entrevista semiestruturada a dois acadêmicos do sexto e oitavo semestres do curso de Licenciatura em Letras Vernáculas, que falaram livremente sobre a relação professor e estudante na sala de aula, destacando aspectos daqueles professores com os quais mais se sentem afastados ou próximos.

Após transcrição das entrevistas, organizamos duas dimensões: Os professores que atuam no curso de Letras Vernáculas (As estratégias didáticas dos professores e o impacto da avaliação na relação e na aprendizagem); A relação entre professores e estudantes (Os conflitos na relação professor-estudante; Como os estudantes se sentem na relação). A seguir apresentamos e discutimos cada uma dessas dimensões e sub dimensões.

\section{Resultados e Discussão}

\subsection{Os professores que atuam no curso de Letras Vernáculas}

Ficou evidente, mediante as entrevistas realizadas em nossa investigação, que os estudantes reconhecem o cansaço dos professores frente às demandas profissionais e problemas pessoais, e expressam sentir seus efeitos ao afirmarem que: "O professor tem que ter plano de aula, tem que cumprir horários, tem que cumprir um bocado de coisa, eu acho. Têm que preencher os diários, aí muitos têm que se deslocar de outra cidade pra vir pra cá. Eu acho que no final das contas eles não têm mais energia e gás pra ficar passando a mão na cabeça dos estudantes no final do dia. Ele já vem de uma viagem, às vezes tem problemas pessoais também. Aí eu acho que eles descontam as angústias deles na gente, enquanto estudantes" (E1).

O depoimento do E1 está de acordo com Magalhães (2013b) ao mostrar que, com as pressões e demandas institucionais, as condições de trabalho do professor universitário tornaram-se diversas e adversas, exigindo muito mais tempo, muitas vezes, dificultando a preparação ou melhora da aula, incompatibilizando as possíveis atualizações e inovações da prática docente. No dia a dia, os professores enfrentam processos de intensificação e precarização do trabalho, o que provoca esgotamento, desmotivação e sofrimento psíquico de muitos profissionais (Daboin \& Ribeiro, 2019), visto que, diante das circunstâncias estressantes, alguns desenvolvem patologias, como depressão, síndrome do pânico, síndrome de Burnout, dentre outras situações que afetam sua saúde, gerando uma constante pressão afetivo-emocional que atrapalha o desenvolvimento dos objetivos pedagógicos e, evidentemente, a relação com os estudantes.

Nessa esteira de discussões, Magalhães (2013b) afirma que a educação torna-se alvo de interesse e elemento essencial do processo produtivo. Na mesma linha de raciocínio, Almeida e Pimenta (2014) inferem que na sociedade contemporânea, a lógica do mercado atua sobre o ensino superior, seguindo os preceitos de um sistema que determina uma aprendizagem rápida, exigindo a obtenção de créditos e diplomas a curto tempo. Assim, o percurso formativo, muitas vezes, não volta sua atenção para a carreira acadêmica dos estudantes, nem mesmo para as culturas da academia e dos jovens.

Assim, segundo E1, os professores descontam seu mal-estar no estudante. Ora eles demonstram autoritarismo, ora se mantêm distantes: "A gente não sente uma aproximação, a gente acha que eles 
parecem que sabem tudo, têm aquela ideia de rei na barriga, sabe?" Para Cavaca et al. (2010), o distanciamento, a falta de diálogo e o autoritarismo são fatores preocupantes que demonstram a manutenção de um modelo hierárquico de ensino. Tal postura por parte dos professores contribui para a educação bancária, na qual, segundo Queiroz et al. (2014), o saber é visto como algo doado, por aqueles que se julgam sábios, àqueles que nada sabem.

Apesar de tais atitudes, Salles e Moletta (2017) destacam que a aproximação com o discente e a sensibilidade no diálogo são fundamentais para a construção do conhecimento. Neste sentido, Magalhães (2013a) salienta que estudantes não-integrados na universidade enfatizaram que se sentiam desconfortáveis com a falta de um ambiente acolhedor e sociável, e desapontados com o que esperavam em termos de qualidade dos relacionamentos com professores e colegas.

O estudo de Souza e Ribeiro (2017) também demostra a visão dos acadêmicos sobre a falta de diálogo e de escuta ao estudante da mesma universidade, argumentando que o docente do ensino superior, muitas vezes, se coloca como soberano, apresentando uma postura inflexível na sala de aula. Souza (2016) evidencia que a flexibilidade é uma qualidade da afetividade e, nessa condição, o professor conhece os estudantes, se coloca disponível, age de forma paciente, sem perder a sua autoridade docente.

Com base em Freire (1994), concordamos com a ideia de que o professor não deve ser visto como o dono da verdade e proprietário de um saber doado aos incapazes, pois, entre outros fatores, a educação vertical não estimula a criação. Assim, o docente deve atuar como facilitador e mediador do processo ensino-aprendizagem e não como única fonte de conhecimento, demonstrando a importância de uma boa interação com o estudante para seu aprendizado (Cosso et al., 2018; Ribeiro, 2010; Cavaca et al., 2010).

Em síntese, o papel do docente é de grande relevância na formação estudantil e a relação professor e estudante não se restringe apenas ao processo educacional formal no ambiente acadêmico. Tal relação envolve sentimentos que deixam marcas na formação do discente. É importante que o professor busque afetividade na comunicação para que a construção do conhecimento seja favorecida (Cosso et al., 2018), pois a demonstração de interesse, cuidado e preocupação vindos do docente podem gerar melhores resultados acadêmicos e atuar positivamente sobre a dificuldade de aprender (Ribeiro, 2010).

\subsubsection{As estratégias didáticas dos professores}

De acordo com Silva (2009), é muito comum a crítica direcionada à didática dos docentes no ensino superior, ou mesmo a falta dela, o que também foi constatado em nosso estudo a partir do estudante E1, o qual evidencia: "Muitos aqui não têm didática. Eles dão umas aulas...tipo assim ... como se eles sabem e a gente não sabe nada, dá pra entender que eles fingem que deram uma aula sem didática nenhuma, aí a gente finge que aprendeu e no final das contas é isso, a gente só tá aqui mesmo pela nota e pronto" (E1). Pelo exposto, não se dá uma relação pedagógica que possibilite aos sujeitos docente e estudantes a "ensinagem", quer dizer a aula entrecruzando com a aprendizagem. E os atores do ato educativo fingem que ensinam ou que aprendem, de modo que no lugar da aprendizagem, a nota rouba a cena.

Destarte, fica evidente que ainda persiste uma preocupação com a nota, a qual, na perspectiva de Silva et al. (2018), pode ter relação com a motivação dos estudantes, que, muitas vezes, está mais voltada para a conquista de uma boa nota do que para a aprendizagem, contribuindo com a competição e a produção de um ambiente que reproduz padrões de uma sociedade capitalista, como referem Porto et al. (2016). Tal representação remete ao binômio aprovação/reprovação e se distancia do processo educativo humanizado, o qual decorre de práticas pedagógicas direcionadas não apenas ao conteúdo, às técnicas ou exames.

Ainda segundo Silva (2009); Santo e Luz (2013), também são comuns os relatos de que o docente domina o conteúdo, mas não sabe bem como transmiti-lo ou não utiliza estratégias de ensino que ajudem os estudantes a compreendê-lo. Mais uma vez encontramos semelhança com nossos resultados, quando o acadêmico diz: "Mesmo que ele tenha todo o conhecimento, mas não sabe passar. Esses que a Didática 
até critica, [...] mas eu acho que, no final das contas, são os melhores que têm. E de maneira geral, eles falam quando a sala tá ruim, que tem que melhorar, que precisa focar mais, eu vejo eles até ajudando" (E1). Assim, o relato de E1 confirma os achados de pesquisas de Oliskovic e Dal Piva (2012); Ribeiro (2010); Cruz (2017); Andrade e Leite (2019), quando afirmam que não basta ao professor universitário dispor de conhecimentos teóricos na área específica, é preciso, também, dominar vários saberes e habilidades pedagógicas para comunicar-se de forma clara, possibilitando o aprendizado por parte dos discentes.

Trazemos para a cena deste debate o enfoque que o estudante dá à escrita no quadro: "Os que se destacam, por incrível que pareça são os que usam aquelas metodologias mais arcaicas assim, [...] eles vão lá ao quadro, eles escrevem as coisas, utilizam o quadro. Isso gera uma aproximação com o estudante, porque o estudante vê aquela disciplina ser escrita lá no quadro e ele acaba se interessando. Pelo interesse, a gente acaba participando mais, os professores acabam fazendo tipo até uma amizade, acolhimento, né?” (E1). Como visto, o universitário aprecia um ambiente de participação proporcionado pela interação com a escrita no quadro.

É defensável que a prática se fortalece quando a relação interpessoal tem por base um espaço de troca, onde é permitida e estimulada a participação dos discentes no processo de construção dos conhecimentos. Nesse sentido, Soares et al. (2016) dizem que o interesse do acadêmico pode estar associado à admiração sentida por pessoas que os compreendam e que podem contribuir com a sua jornada. Assim, a admiração pelos docentes é capaz de ativar a motivação estudantil, criando condições para que os discentes gostem da disciplina e se aproximem do professor.

Ainda em relação às estratégias didáticas, o estudante mostra como uma aula sem movimento e sem relação com a prática profissional do professor em formação, pode ser desestimulante: "Na sala de aula todo mundo tá ali, tá vendo aquela disciplina em uso mesmo, e você fica alegre, você se empolga. Aí pense o contrário: você chega na sala de aula e o professor chega, fica sentado lá na cadeira dando aula. O cara não se levanta em nenhum momento para pegar um piloto, o cara não faz nem um risco no quadro" (E1).

O estudante E1 ainda afirma que: "Já tive professor que desde o início do semestre até o final não escreveu nada no quadro, nada mesmo. Como é que pode apresentar uma matéria assim!? A gente não sente nem prazer em estar assistindo uma aula dessa!" (E1). Percebemos, portanto, que o acadêmico espera encontrar profissionalismo e um docente ativo, mesmo que na aula use apenas a lousa. Já o estudo de Salles e Moletta (2017) traz as percepções de estudantes que esperam diversidade no uso de estratégias de ensino e que, também, dominem o conteúdo, abordando-o de forma compreensível e articulado à realidade dos universitários.

Complementando tal ideia, nos resultados da pesquisa de Araújo et al. (2014), os universitários desaprovam aqueles professores vistos como monótonos, os quais contribuem para sua desmotivação, destacando, também, os que apresentam alguma dificuldade na condução da aula, os que parecem ter pouco interesse em relação ao que estão ensinando, aqueles que exigem atividades em excesso, usam repetidamente ou unicamente um recurso didático e, por fim, aqueles que não aproximam teoria e prática na sala de aula.

Com base nas palavras de Porto et al. (2016), compreendemos que o docente afetivo com os estudantes busca uma aproximação e procura gerar condições para a motivação deles, atuando de modo a reduzir o distanciamento entre o nível de conhecimento real e o que os estudantes poderão construir com sua ajuda. As aulas desenvolvidas sem uma base afetiva, contrariamente, centram-se apenas no cumprimento do conteúdo estabelecido.

Os acadêmicos investigados por Cavaca et al. (2010) consideraram como pontos positivos na relação com os professores, além do profissionalismo, as situações em que sentem respeito mútuo, segurança, atenção, compreensão, prestatividade por parte dos docentes e disponibilidade deles ao diálogo, o que também foi percebido na nossa pesquisa, a partir da visão dos acadêmicos. Com efeito, para Schwartz e Bittencourt (2012), o professor deve ter conhecimento sobre os conteúdos, 
compartilhamento e participação no coletivo de trabalho, atitudes pessoais de respeito e empatia ao outro, reconhecimento da própria incompletude, abertura à crítica e à revisão de suas ações e conceitos.

\subsubsection{O impacto da avaliação na relação e na aprendizagem}

A avaliação permite a reflexão acerca da prática, levando em consideração os modos de ensinar e desenvolver estratégias de ensino favoráveis às aprendizagens (Silva et al., 2018). Todavia, detectamos sua aplicação com finalidades que fogem do contexto da verdadeira função avaliativa, mediante o uso de instrumentos de controle como exames e provas, que distanciam a relação professor-estudante. (Araújo et al., 2015; Cosso et al., 2018).

Com efeito, Santo e Luz (2013) mostram a insatisfação dos estudantes diante de instrumentos de avaliação que impedem a socialização das suas construções acerca da disciplina. Nesse mesmo sentido, Araújo et al. (2015) destacam a importância das avaliações ocorrerem de forma multidimensional, contínua, progressiva e inclusiva. Também que, a prova não é suficiente para avaliar e que há outras formas de avaliação, já que os estudantes vivenciam um processo de aprendizagem gradativo, o qual não corresponde àquele momento da realização da prova.

A propósito das práticas avaliativas, nossos sujeitos, em primeiro lugar, focalizam uma docente que reconsiderou a avaliação ao sentir que a turma apresentava dificuldades: "A professora $\mathrm{X}$ viu que a turma não teve o rendimento tão bom e parece não ter entendido muito bem, a aprendizagem não foi fluida, e ela, sem problema nenhum, fez questão de dar uma outra chance, de fazer a avaliação para aqueles que tiveram uma nota mais baixa. Ela contou com o apoio de um outro estudante que tinha tido uma compreensão melhor para ajudar os colegas" (E2).

A partir desse relato podemos confirmar as palavras de Silva et al. (2018), quando dizem que ao encontrar problemas de aprendizagem na sua disciplina, o professor comprometido com sua prática e que reflete sobre sua docência, lança mão de alternativas que ajudem a reduzir a reprovação. Neste sentido, Luckesi (2008) acrescenta a necessidade do interesse na aprendizagem do estudante e não apenas na aprovação dele. Assim, vimos que a professora citada mostrou preocupação com a aprendizagem e repensou a avaliação inicial que não tinha gerado bom resultado, possibilitando uma oportunidade para que fosse refeita, embora ainda pareça centrada na prova como único instrumento avaliativo.

Além disso, ainda destacamos a participação do acadêmico que teve melhor compreensão e auxiliou os colegas, mostrando que a cooperação faz parte do processo de aprendizagem, o que é notado nas pesquisas realizadas por Souza (2016), Salles e Moletta (2017) nas quais são evidenciadas atitudes de ajuda e colaboração dos estudantes para com os colegas, diante das dificuldades de aprendizagem.

Merece registro o sentimento decorrente da atitude do professor que realiza um processo avaliativo considerando a participação dos discentes: "De maneira geral eles falam quando a sala tá ruim, que tem que melhorar, que precisa focar mais, eu os vejo até ajudando, pede pra ir no quadro, faz atividade valendo décimos. Tem uma professora, em especial, que quando a gente estava fraco assim, ela botava a gente pra ir ao quadro. Qualquer coisa que a gente fazia, ela dava alguma nota pra gente e isso ajudou bastante a gente, com relação a ter o interesse na disciplina mesmo, porque você indo lá no quadro, você vivenciava aquela matéria. Foi bem importante, eu achei bem legal esse jeito que ela trabalhou" (E1).

É notório, nesta narrativa de E1, o quanto a nota é valorizada no ensino superior. Esta é uma controvérsia que pode embalar o debate sobre a avaliação da aprendizagem. Trata-se de uma avaliação, cuja lógica é a excelência e não a formação. Enquanto aquela estigmatiza e seleciona os indivíduos, esta busca a regulação da aprendizagem, a fim de melhorá-la. Pelo exposto, não nos pareceu que a avaliação tenha sido diversificada, atendendo à diversificação dos conteúdos trabalhados. Ao contrário, a professora, no lugar de investigar o quanto os estudantes compreenderam ou não os conceitos trabalhados de modo a aplicá-los na prática, ela "dá" pontos àqueles que acertam as questões, premiandoos. Todavia, uma docente observada no trabalho de Ribeiro e Santos (2020), cuja avaliação processual e formativa foi feita em momentos diferentes, contou com a variação de instrumentos e buscou 
acompanhar o ritmo da aprendizagem dos estudantes, resultou em ajustes nas estratégias de ensino ao longo das aulas e na aprendizagem significativa dos discentes.

Por certo, a avaliação formativa, voltada para a aprendizagem, pode contribuir para o desenvolvimento do educando em sentido crítico, ético, pessoal, profissional e cognitivo (Silva \& Mendes, 2017). No entanto, é possível percebermos que o acadêmico sente o impacto das práticas contrárias, ou seja, aquelas pautadas em uma avaliação de base classificatória: "Então é uma avaliação compulsória, não uma avaliação efetiva, aquela que Luckesi costuma falar que é amorosa, que é acolhedora? Não. É um exame mesmo, prova, pra regular você, pra regular o quanto você sabe ou não daquela disciplina, então acho que teve sim impacto na aprendizagem, mas foi negativo" (E2). Nesse sentido, de acordo com Araújo et al. (2015) o exame classificatório é excludente e seletivo, já que considera apto aquele que obtiver boa nota, podendo contribuir, entre outros fatores, para a elevação do número de reprovações e até mesmo para a evasão de estudantes, dificultando as possibilidades de conclusão do ensino superior. A respeito das consequências negativas dos exames, para Luckesi (2008), medir as aprendizagens sob a forma de verificação gera consequências negativas aos educandos, como, por exemplo, a ameaça e o medo da reprovação.

Merece registro o destaque para uma docente vista como autoritária, cuja prática tinha princípios da avaliação como punição: "Teve casos isolados assim de professor fazer terror psicológico com o estudante, com a turma. De professor tirar a prova 1 hora antes do horário devido, porque alegou que a gente saía mais cedo durante as aulas, sendo que isso era total equívoco" (E2). Segundo o estudante, "Enquanto ela estava aplicando a avaliação, ela ficava corrigindo a avaliação da turma anterior e ela ficava rindo e debochando, falando: 'Nossa, que babaca, como é que dá uma resposta dessa?' Enquanto a gente estava fazendo a avaliação. Então, isso gera mais tensão e preocupação de que a mesma situação pudesse se repetir com a gente, posteriormente" (E2).

Tal relato vai ao encontro de Silva e Mendes (2017) quando evidenciam a existência de um clima de tensão no momento da aplicação da prova. Isso desestabiliza emocionalmente o estudante e pode suscitar impactos negativos no seu desempenho. Nesse caso, a tensão torna-se ainda maior devido a atitude docente de recolher a prova antes do horário de término, como punição, tendo como justificativa o horário de saída dos estudantes durante as aulas, o que acaba provocando nervosismo e dificuldade de concentração, como o acadêmico complementou: "Isso dificultou a aprendizagem da gente porque a gente estava fazendo as coisas, respondendo, do jeito que estava envolvido na mente no momento, não do que a gente tinha aprendido da disciplina, mas responder por responder porque tinha que terminar logo, porque tinha que entregar logo, entendeu?" (E2).

Quanto à forma como estava sendo corrigida a prova da outra turma (expondo os estudantes com comentários ofensivos), também contribuiu para desestabilizar quem estava respondendo a prova, produzindo preocupação e medo de ser exposto da mesma maneira. De acordo com Rozendo et al. (1999), por descuido relacional, muitas situações constrangedoras podem ser observadas na sala de aula, como as repressões ao acadêmico diante de outras pessoas, gerando desconforto, desmotivação e desinteresse pela disciplina. Para Oliskovic e Dal Piva (2012), muitos docentes desejam manter a sua autoridade e autoestima praticando atitudes protetoras, como formalismo na comunicação, exagero no nível de exigência nas provas, uso de ironia e sarcasmo. Souza e Ribeiro (2017) também encontraram revelações de que muitos docentes coagem o discente, duvidando da sua capacidade cognitiva, em um comportamento que, segundo os estudantes, é devido à falta de respeito, de ética e de profissionalismo por parte do professor.

De acordo com Salles e Moletta (2017), faz parte da responsabilidade docente a criação de um clima propício à aprendizagem e o bom humor do professor em sala de aula é valorizado pelos discentes nesse contexto. Além disso, Aita e Araújo (2006) complementam que a afetividade decorre de um clima em que há, principalmente, respeito ao estudante e ao seu desenvolvimento sócio cognitivo. Se há ausência de respeito e de valorização ao que se constrói no ambiente educativo, o clima predominante é tenso e compromete-se o desenvolvimento da aprendizagem. O respeito também foi um dos elementos 
primordiais em torno da relação professor-estudante, de acordo com as representações sociais dos participantes das pesquisas de Souza (2016) e Cosso et al. (2018).

Dando continuidade à análise das narrativas dos nossos entrevistados, a mesma professora foi lembrada quanto à falta de acessibilidade nos questionamentos da turma: "Ela não respondia nada, mesmo que a pergunta tivesse ambígua. Algumas questões eram bem ambíguas e ela simplesmente se negava a ajudar e realmente tirou a prova 1 hora antes do tempo devido" (E2). Observamos pelo relato, que a docente se mantinha distante dos universitários até mesmo no auxílio em relação a dúvidas, atitude contrária ao que foi observado por Ribeiro e Santos (2020) sobre a prática de determinada professora a qual, centrada na aprendizagem, se manteve sempre próxima aos estudantes, tirando dúvidas e observando o desenvolvimento dos discentes durante a avaliação. Se não há clima para esclarecimentos de dúvidas e questionamentos, a autoridade acaba sendo confundida com autoritarismo, sendo que apenas o professor tem a fala, dificultando até o diálogo entre os próprios colegas (Silva, 2009). Todavia, para Freire (2002), o docente autoritário limita a liberdade do estudante e fere seu direito à curiosidade.

\subsection{A relação entre professores e estudantes}

Os acadêmicos entrevistados exibiram suas percepções acerca da relação estabelecida com os professores. Por um lado, o estudante deixa clara sua insatisfação com a relação de distância e formalismos ao afirmar que: "A maioria são mais reclusos, eles evitam contato com o estudante [...] em geral, eles são mais fechados, eles não deixam a gente chegar neles. [...] Em nenhum momento os professores procuram saber como é que os estudantes estão. Eles nunca perguntaram como é que foi o dia de algum estudante, não perguntam se o estudante tá passando alguma dificuldade, quando tá com algum rendimento ruim na disciplina, eles não chegam e perguntam o que é que tá havendo. Acho que é uma relação muito distante" (E1). Pelo exposto, é notório que o discente sente falta do diálogo no contato do dia a dia. Nessa perspectiva, Souza (2016) observa que a valorização do diálogo e a busca por conhecer os universitários, a escuta sobre o que eles pensam, é fundamental para resolver conflitos e diminuir o distanciamento entre estudantes e professores.

$\mathrm{Na}$ visão discente, também existe uma distância entre o que se prega e o que se faz, e isso dificulta a relação, na medida em que: "Os professores mostram que a educação tem esse caráter transformador, tem esse caráter humano. Eles falam tanto em solidariedade, mas quando chega em sala de aula eu não vejo isso, eu não vejo professor... sei lá... se aproximando dos estudantes, querendo saber como é que tá a semana, se tem muita atividade acumulada, né?” (E1). Na pesquisa de Araújo et al. (2014), os universitários também destacaram que há docentes cujo discurso se contradiz com a postura profissional. Destarte, Cavaca et al. (2010) inferem que seus participantes esperam encontrar no professor coerência entre os valores defendidos e as ações desencadeadas por tais profissionais.

Para Silva (2009), o professor deve apreciar nos estudantes, seus sentimentos e opiniões, já que tais atitudes contribuem para facilitar a aprendizagem, na medida em que a manifestação de carinho auxilia o estudante a se relacionar e assimilar melhor o conteúdo proposto. Segundo Soares et al. (2016), quando se desenvolvem relações de respeito e interesse mútuo, pode-se gerar admiração entre estudantes e professores e favorecer o aproveitamento das aulas com mais harmonia. Se o professor se interessa pelo progresso dos estudantes e demonstra tal atitude, ele estimula a autoconfiança dos estudantes e pode contribuir para que sejam bem mais sucedidos em suas realizações. Já para os professores que são impessoais e indiferentes, a tendência é que aconteça o contrário (Silva, 2009).

E2 conta que uma docente deixou marcas em sua trajetória e de seus colegas: "A professora fazia pressão psicológica, terror psicológico com a turma. Hoje, tanto eu quanto outros colegas relatam isso como uma das piores experiências da graduação em relação a professores especificamente" [...] "Ela costumeiramente fazia piadinhas na sala de aula, debochava dos estudantes" (E2). Em semelhança, no trabalho realizado por Andrade e Leite (2019), os acadêmicos destacaram, entre as situações que lhes causaram mal-estar: as ameaças, arrogância, falta de compreensão frente às dificuldades dos discentes, 
desrespeito, uso de autoridade para se desfazer do conhecimento dos estudantes, demonstração de superioridade, de desprezo, autoritarismo, deboche, falta de ética e falta de humildade. São situações que, vindas dos docentes, despertaram, segundo os participantes do estudo, raiva, inconformismo, insegurança, vergonha, até mesmo vontade de abandonar o curso.

Após citar o efeito decorrente dos prazos de entrega de atividades ou realização de avaliações, o estudante E2 expressou seu sentimento diante da experiência com a postura da professora: "Apesar de ter sofrido muitas pressões psicológicas na universidade por conta dos prazos, enfim... essa foi uma das minhas piores experiências que me levou ao banheiro para eu chorar mesmo, porque eu desabei naquele momento. Então, eu acho que esse foi um episódio marcante para mim (e pra outros estudantes também, pelo que eu tenho conhecimento deles, dividindo experiências). [...] Eu acho que apesar de ter estudantes com perfis diversos na minha turma, certamente, espero que nenhum aja como ela agiu, entendeu? Botando tanta pressão e sem necessidade. [...] Acho que isso marca nossa trajetória acadêmica de uma forma muito negativa, e a aprendizagem também" (E2).

Apesar desses depoimentos, os estudantes contam suas vivências positivas. Assim, E2 diz que "Com a maioria dos professores a gente teve uma relação boa, amigável [...]". Além disso, evidencia como é importante sentir a atenção do docente, citando professores afetivos: "Eu até destaco alguns professores (a maioria da área de literatura) que te olham como ser humano, professores que chegam assim: O que é que está acontecendo? Por que você não tá se entrosando muito? Eles não estão preocupados só em formar o profissional, mas eles estão preocupados em formar o cidadão! Então, isso me impactou de forma extremamente positiva" (E2). Neste mesmo sentido, merece registro o fato de que os participantes do estudo de Andrade e Leite (2019) indicaram, além da compreensão docente para com o comportamento do estudante, da escuta pelo que ele tem a dizer e do interesse pelo seu conhecimento, as situações que interferem positivamente na sua aprendizagem: demonstração de entusiasmo, boa relação interpessoal, motivação e valorização do discente, além de acreditar na capacidade e no seu potencial. Segundo os acadêmicos, tais situações lhes provocaram bem-estar, motivação, sensação de liberdade para aprender, vontade de desenvolver de forma ainda melhor suas atividades e melhor se relacionar com o professor e colegas, sentimento de gratidão e respeito pelo professor, espontaneidade, carisma, simplicidade e humildade.

Ainda em relação às vivências positivas, o estudante E2 cita uma docente que diante do mau desempenho da turma, contornou a situação de forma acolhedora: "Eu percebi que ela via que a aprendizagem não dependia só dela, mas é de todo um conjunto, é de todo um trabalho em grupo, entende? Então isso para mim teve impacto muito positivo e é um exemplo pra mim, de docente" (E2). Segundo os estudantes pesquisados por Souza e Ribeiro (2017), o professor flexível em sua atuação constrói com os estudantes uma relação de respeito e reciprocidade e busca soluções conjuntas para os problemas que surgem na sala de aula. Com efeito, para Viana e Silva (2017), a construção de uma relação afetiva, democrática e colaborativa, cujo poder de decisão e ação parte do compartilhamento entre docentes e discentes, cria condições para um ambiente favorável à construção, produção, significação e ressignificação dos conhecimentos, compreendendo essa relação como complementar.

\subsubsection{Os conflitos na relação professor e estudante}

No tocante aos conflitos na relação entre professor e estudante, os colaboradores não relataram muitas colisões. Porém, ficou evidente nas narrativas dos estudantes entrevistados, que conflitos podem ser provocados, quando se mantém a ideia da extrema superioridade do docente em relação aos discentes.

Nas palavras do estudante E1: "O conflito mais acirrado foi em relação a um professor estrangeiro. Por ele ser de fora, achava que nós somos inferiores a ele. Aí teve essa discussão na sala de aula ao ponto de um estudante deixar parecer que ele fosse um colonizador. Aí o professor se sentiu ofendido, mas no final das contas tudo deu certo. Ninguém exaltou os ânimos, mas eu sei que aqui de vez em quando rola umas perseguições por parte de professores com estudantes, né?” (E1). Assim, ficou manifesto que 
muitas vezes os conflitos podem ser gerados a partir de uma visão equivocada que se tem sobre o professor, reforçando, portanto, a importância do diálogo para que possa auxiliar o docente no conhecimento dos discentes, de suas inseguranças, opiniões, medos, perspectivas, expectativas, de forma que possa direcionar o trabalho e, principalmente, mediar a aprendizagem (Silva, 2009), além de facilitar na condução de conflitos.

Destacamos, ainda, a relevância da postura flexível do professor nesse processo, pois as relações de respeito e amizade podem ser facilmente fragilizadas devido à ausência de flexibilidade, visto que o indivíduo inflexível "tende a enxergar apenas as suas razões e não cede nem um pouco às ponderações do outro" (Souza \& Ribeiro, 2017, p. 167).

O estudante E1 ainda reforça que: "Já vi um conflito em sala de aula. Nunca aconteceu comigo, mas eu já presenciei. Foi um conflito mais de ideologia política". Ainda, de acordo com o mesmo E1: "O professor pensa uma coisa, outro estudante pensa outra coisa, mas no final das contas todos se entendem" (E1). Diante disso, compreendemos que é comum a ocorrência de conflitos já que existe a liberdade e a diversidade de pensamento. Desse modo, reforçamos o papel mediador do docente, inclusive na condução de situações que ocorrem no cotidiano da sala de aula, visto que, na opinião de Souza e Ribeiro (2017), a falta de mediação e de liderança do professor gera nos acadêmicos a percepção de distanciamento do profissional em relação a um de seus grandes papeis que é gerir conflitos.

Silva (2009) apresenta ideias semelhantes e afirma a importância de que o professor tenha conhecimento sobre os fatores que geram os conflitos, para aumentar a possibilidade de controlar e de encontrar os melhores meios para solucioná-los, tendo em vista que os conflitos entre professores e estudantes limitam e dificultam as proposições de mudanças (Cavaca et al., 2010). De acordo com Silva (2009), a atividade intelectual pode ser afetada pelas relações conflituosas, gerando baixo rendimento.

Já o acadêmico E2 apresenta sua visão em torno da ausência de conflitos na relação entre professores e discentes, frisando apenas conflitos da coletividade estudantil: "Acredito que, se fosse fazer uma avaliação geral da relação entre professor-estudante e estudante-estudante, é tranquila. Não tem muito atrito, não tem muito conflito. Foi mais aquele atrito de primeiro e, segundo semestre, mas logo todo mundo viu suas afinidades com seus colegas e meio que se dividiu a turma, mas sempre mantendo no geral uma relação respeitosa" (E2).

Por fim, assinalamos que em uma turma onde estão presentes diferentes culturas, fica difícil a não existência de conflitos e de opiniões diversas, todavia, através do respeito e das conversações em grupo se constrói um ambiente de convivência amistosa. Assim, o professor precisa auxiliar os estudantes, identificar suas necessidades, praticando e estimulando o respeito mútuo e preservando a dignidade de todos os sujeitos, para atingir equilíbrio na resolução dos problemas pessoais e coletivos.

\subsubsection{Como os estudantes se sentem na relação}

A propósito dos sentimentos expressos pelos estudantes na relação que estabelecem com os professores, os universitários relatam que há muita cobrança, inclusive de assuntos que não ficaram bem claros ou que não foram trabalhados em aula, o que se soma aos problemas que já fazem parte da rotina estudantil, como a quantidade de trabalhos, de provas e o choque entre as atividades das disciplinas. Além disso, há destaque para a desistência ou adiamento da matrícula em disciplinas por parte daqueles que não conseguem se adaptar ao perfil de professores exigentes. Quando eles desistem, fica a ideia que o estudante não quer nada, como podemos observar no excerto: "Tem estudante que não quer nada, aí vai no começo da disciplina acha que vai ser difícil e acaba largando no meio do caminho" (E1).

Pelos relatos, notamos que o acadêmico sente uma certa pressão por conta da cobrança de conteúdos, como vimos nas palavras do estudante: "Tem alguns professores que dificultam mesmo a permanência do estudante, cobrando muita coisa, mas são raros, não são todos, não" (E1). E ainda, segundo ele, acontecem situações em que são cobrados conteúdos além do que foi trabalhado em aula: "Eles não apresentam a disciplina, quando chega na prova querem cobrar coisas que não deram, aí a 
gente acaba recorrendo a livros de nível médio pra trazer coisas que eles nem deram em sala de aula. Teve um professor que não deu essa abordagem toda didática da disciplina, veio com um livro teórico enorme, afastando todo mundo, e eu tive um colega que saiu justamente por causa disso, por causa desse livro enorme. Ele viu que a disciplina não seria bem ministrada, aí ele pegou e desistiu, porque ele achou que ia ser bem densa, não ia ser nada daquilo que ele estava pensando" (E1). Diante de tal situação conflituosa, cabe aos professores a reflexão sobre a sua prática, a fim de contribuir para o interesse e êxito dos estudantes. Todavia, ao que nos parece, não significa que os professores tenham que ter um comportamento laissez-faire.

Merece registro que a investigação de Almeida (2007) também apresentou o relato de um estudante, o qual precisou recorrer a livros de ensino médio para compreender conteúdos tidos como básicos do curso. Todavia, muitas vezes, os docentes não estão disponíveis para acompanhamento daquilo que se espera do universitário em termos de base, o que demanda da universidade políticas que visem o engajamento estudantil.

Quanto à desistência de disciplinas, a relação estabelecida com os professores pode influenciar a relação do discente com os componentes curriculares. Ribeiro (2010) evidencia que as disciplinas ministradas por docentes que conseguem manter uma relação melhor com os estudantes, são mais apreciadas pelos discentes. Além disso, universitários pesquisados por Andrade e Leite (2019) descreveram, dentre as situações que lhes causaram mal-estar e interferiram de modo negativo na sua aprendizagem, as experiências com autoritarismo e indiferença de docentes, que acabaram desencadeando a exclusão de disciplinas.

Neste mesmo sentido, um dos participantes da nossa pesquisa declara que "Nem adianta se a disciplina for uma disciplina fácil, e tem um professor carrasco, de cara fechada, que é mal educado, chato. Ninguém vai querer saber se a disciplina é fácil ou não, a gente vai ficar assistindo a aula todo desgostoso" (E1). Já o estudante E2 destaca que colegas permaneciam em uma determinada disciplina, no entanto, sentiam medo de possíveis repressões: "Eu gostava da disciplina, mas tinha pessoas na minha turma que aprendiam a disciplina na tora, à força, mas não porque queriam aprender. Era simplesmente pra não ser chamado a atenção, entende? Pra ela não olhar torto e ficar perguntando coisas e ficar constrangendo por não saber responder, entende?” (E2). Tais depoimentos entrecruzam com o estudo de Aita e Araújo (2006), ao revelar que muitos acadêmicos podem desenvolver aversão por algumas disciplinas, quando o conhecimento adquirido foi fruto de um processo impessoal ou resultado de coerção por parte do professor.

$\mathrm{Na}$ opinião discente, além de problemas de ordem pessoal, que não são levados em consideração pelos docentes, acaba ocorrendo uma sobrecarga em torno das atividades, das datas de entrega de trabalhos, realização de provas e seminários, como verificamos nesta narrativa: "Eu já passei, assim, um sufoco em relação à quantidade de trabalhos pra fazer, porque tem vez que fica acumulado muito no meio pro fim do semestre e eles não fazem uma divisão entre eles mesmos e parece que eles não sentam nem discutem: 'Oh, a gente vai deixar essa semana pra tais professores pra fazer tais atividades'. Parece que eles pegam e marcam de qualquer jeito e no final se chocar, chocou" [... "Eu acho que isso, essa falta de organização deles mesmos, até entre eles, assim, dificulta até a nossa saúde mental aqui dentro da universidade, mas acho que eles nem ligam pra isso, acham que a gente tem que aceitar tudo que eles dão". (E1)

Merece registro a semelhança desses resultados com aqueles do estudo de Souza e Ribeiro (2017), nos quais os discentes consideraram indesejável o fato de professores desconhecerem as condições psicológicas dos estudantes. Segundo as autoras, as pressões psicológicas sentidas por tais sujeitos, decorrentes de estresses de ordem pessoal, intelectual, socioeconômica, curricular e pedagógica, podem ocasionar sentimentos de incapacidade diante das demandas universitárias, além de ansiedade e até quadros depressivos agravantes que exigem ajuda profissional.

Ainda nesse contexto, o discente mostra-se incomodado com a coincidência de atividades pedidas pelos professores, o que dificulta a concentração nas aulas, visto que: "Tem dias que você tem duas apresentações. Tem dia que a professora tá dando uma aula de um assunto importante pra uma prova, 
mas depois você tem uma prova ou tem uma apresentação, aí você não consegue nem prestar atenção" (E1). Do mesmo modo, Souza (2016) destaca que para seus entrevistados, a afetividade representa sensibilidade e a prática da escuta sensível do docente, especialmente ao perceber que algo está diferente com o discente. Neste sentido, o professor, praticando a empatia, pode se colocar na posição do estudante, ouvindo-o, discutindo e refletindo junto com ele em direção a melhores formas de condução do trabalho (Salles \& Moletta, 2017; Porto et al., 2016).

\section{Considerações finais}

As narrativas dos estudantes evidenciam o reconhecimento da sobrecarga dos professores universitários e o desenvolvimento de uma prática fundamentada no paradigma tradicional, que representa a figura do professor austero, autoritário, centrado na transmissão dos conteúdos curriculares e nos exames, fatores que podem contribuir para o distanciamento que, na maioria das vezes, ocorre com os discentes.

No tocante às práticas docentes, os acadêmicos sentem que alguns professores carecem de variação das estratégias didáticas e, em certos casos, apresentam dificuldade em socializar o conhecimento. Além disso, os estudantes relatam suas percepções acerca de posturas restritivas, punições, pressão psicológica, dificuldades no esclarecimento de dúvidas e em torno das possibilidades de remanejamento diante da sobrecarga de atividades, como fatores que contribuem para a falta de interação e que dificultam os processos de ensino e aprendizagem.

Em contrapartida, os estudantes apreciam as atitudes do professor que chama atenção da turma e avisa quando precisam melhorar, atitudes em que apresentam abertura e estímulo para a participação estudantil, além do trabalho em coletividade na resolução de problemas e conflitos, tendo como meta a aprendizagem. Fica evidente que os sujeitos da pesquisa têm consciência quanto à relação existente entre o docente e a disciplina ministrada por ele, ou seja, eles podem gostar de determinado componente curricular por causa do professor que o ministra.

Em suma, os discentes valorizam e sentem falta de uma aproximação com os docentes, de um professor que se preocupe com o estudante e demonstre tais atitudes. Ademais, expressam os efeitos das práticas formais e, principalmente, do autoritarismo, como entrave ao estabelecimento de um ambiente favorável à aprendizagem. Aspiram uma relação na sala de aula pautada no diálogo e na empatia, confirmando os achados da literatura e reforçando a importância do papel mediador do professor. Dentro desse escopo, os resultados da presente pesquisa sugerem a realização de outros estudos para aprofundamento de um debate em torno da temática.

\section{Agradecimentos}

Agradecemos ao Conselho Nacional de Desenvolvimento Científico e Tecnológico (CNPQ) pelo apoio e financiamento desta pesquisa. 


\section{Referências}

Aita, G., \& Araujo, C. de S. A. (2006). Afetividade e aprendizagem no ensino superior. Revista da Educação, 6 (1), 49-60. https://doi.org/10.25110/educere.v6i1.2006.158

Almeida, M. I. de; Pimenta, S. G. (2014). Pedagogia universitária - valorizando o ensino e a docência na universidade. Rev. Port. de Educaşão. 27 (2), 7-31. https://doi.org/10.21814/rpe.6243

Almeida, W. M. de (2007). Estudantes com desvantagens econômicas e educacionais e fruição da universidade. Cad. CRH, 20 (49), 35-46. https://doi.org/10.1590/S0103-49792007000100004

Andrade, A. K. B. B. de, \& Leite, M. D. B. (2019). A afetividade na relação professor-aluno e suas implicações na aprendizagem em contexto universitário. Id Online Rev. Mult. Psic.,13 (46), 58-84. https://doi.org/10.14295/idonline.v13i46.1869

Araújo, M. V. de, Silva, J. W. B. da, \& Franco, E. M. (2014). Motivação para o aprendizado em estudantes de graduação em Psicologia. Revista Psicologia: Teoria e Prática, 16(2), 185-198. http://pepsic.bvsalud.org/scielo.php?script=sci_arttext\&pid=S1516-

$36872014000200016 \& \operatorname{lng}=\mathrm{pt} \& \operatorname{lng}=\mathrm{pt}$

Araújo, S. C. F., Carvalho, D. M. de, Pinheiro, F. V. R., Dias, L. S., \& Martins, M. da C. R. (2015, de 26 a 29 outubro). Avaliação da aprendizagem no ensino superior: sob a lupa discente. XII Congresso Nacional de Educação (EDUCERE), Paraná, Brasil. https://educere.bruc.com.br/arquivo/pdf2015/18058_9502.pdf

Augusto, C. A., Souza, J. P. de, Dellagnelo, E. H. L., \& Cario, S. A. F. (2013). Pesquisa qualitativa: rigor metodológico no tratamento da teoria dos custos de transação em artigos apresentados no Congresso Sober (2007-2011). Rev. Econ. Sociol. Rural, 51 (4), 745-764. https://doi.org/10.1590/S010320032013000400007

Cavaca, A. G., Esposti, C. D. D., Santos-Neto, E. T., \& Gomes, M. J. (2010). A relação professor-aluno no ensino da Odontologia na Universidade Federal do Espírito Santo. Trab. educ. saúde [online], 8 (2), 305-318. https://doi.org/10.1590/S1981-77462010000200008

Cosso, E., Franco, M. L. P. B., \& Fernandes, J. da S. G. (2018). Representações sociais sobre relação professor-aluno no ensino superior. Revista Brasileira de Ensino Superior, 4 (3), 5-23. https://doi.org/10.18256/2447-3944.2018.v4i3.2389

Cruz, G. B. da (2017). Didática e docência no ensino superior. Rev. Bras. Estud. Pedagog. [online], 98 (250), 672-689. https://doi.org/10.24109/2176-6681.rbep.98i250.2931

Daboín, M. M. G., Ribeiro, M. L. (2019). O perfil dos estudantes ingressantes no curso de Pedagogia. Revista Nuances: estudos sobre educação, 30 (1), 312-326. https://doi.org/10.32930/nuances.v30i1.6765

Freire, P. (1994). Educaşão e mudança, Paz e Terra.

Freire, P. (2002). Pedagogia da autonomia: saberes necessários à prática educativa, Paz e Terra. 
Luckesi, C. C. (2008). Avaliação da aprendizagem escolar, Cortez.

Magalhães, M. de O. (2013a). Sucesso e fracasso na integração do estudante à universidade: um estudo comparativo. Revista Brasileira de Orientação Profissional, 14(2), 215-226. http://pepsic.bvsalud.org/scielo.php?script=sci_arttext\&pid=S1679$33902013000200007 \& \operatorname{lng}=\mathrm{pt} \& \operatorname{lng}=\mathrm{pt}$

Magalhães, S. M. O. (2013b). Trabalho, pesquisa e ensino: tensões e desafios para a docência no ensino superior. Psicologia Ensino $\quad e \quad$ Formação, 4(1), 60-78. http://pepsic.bvsalud.org/scielo.php?script=sci_arttext\&pid=S2177-

$20612013000100005 \& \operatorname{lng}=\mathrm{pt} \& \operatorname{lng}=\mathrm{pt}$

Oliskovic, K., \& Dal Piva, C. (2012). As estratégias didáticas no ensino superior: quando é o momento certo para se usar as estratégias didáticas no ensino superior?. Rev. de Educaşão. 15 (19), 111-127. https://revista.pgsskroton.com/index.php/educ/article/view/1710/1635

Porto, C. de M., Santos, F. M. F. \& Cruz, M. A. da. (2016, de 16 a 20 maio). Uma revisão bibliográfica da relação entre professor e aluno no ensino superior sob a ótica da afetividade. $9^{\circ}$ Encontro Internacional de Formação de Professores (ENFOPE), Sergipe, Brasil. https://eventos.set.edu.br/enfope/article/view/2100/527

Queiroz, F. C., Souza, I. C. de, Farber, J. C., Luz, M., \& Moraes, P. R. de (2014). As dificuldades vivenciadas pelos professores do ensino superior frente à transição paradigmática da educação: desafios e possibilidades. Educaşão em Foco (Amparo) [online], 6, 139 https://portal.unisepe.com.br/unifia/wpcontent/uploads/sites/10001/2018/06/9dificuldades_prof_superior.pdf

Ribeiro, M. L. (2010). A afetividade na relação educativa. Estudos de Psicologia, 27(3), 403412. https://doi.org/10.1590/S0103-166X2010000300012

Ribeiro, M. L., \& Santos, M. J. de O. (2020). Avaliação da aprendizagem: contribuições da pesquisa-ação colaborativa. Revista de Iniciação à Docência, 5 (1), 84-99. https://doi.org/10.22481/rid-uesb.v5i1.6810

Rozendo, C. A., Casagrande, L. D. R., Schneider, J. F., \& Pardini, L. C. (1999). Uma análise das práticas docentes de professores universitários da área de saúde. Revista Latino-Americana de Enfermagem, 7(2), 1523. https://doi.org/10.1590/S0104-11691999000200003

Salles, W. das N., \& Moletta, A.F. (2017, de 28 a 31 agosto). Papel docente e discente na universidade: estudo das percepções de estudantes universitários de Educação Física. XIII Congresso Nacional de Educação (EDUCERE), Paraná, Brasil. https://educere.bruc.com.br/arquivo/pdf2017/24924_12662.pdf

Santo, E. do E, \& Luz, L. C. S. da. (2013). Didática no ensino superior: perspectivas e desafios. Revista Saberes, (8), 58-73. https://periodicos.ufrn.br/saberes/article/view/2201

Schwartz, S., \& Bittencourt, Z. A. (2012, de 29 julho a 01 agosto). Quem é o "bom professor" universitário? Estudantes e professores de cursos de Licenciatura em Pedagogia dizem quais são as (ideais) qualidades deste profissional. IX Seminário de Pesquisa em Educação da Região Sul (ANPED SUL). http://www.ucs.br/etc/conferencias/index.php/anpedsul/9anpedsul/paper/viewFile/1423/976 
Silva, F. O. da, Ribeiro, M. L., \& Almeida, L. R. de M. (2018). A avaliação "é a bola girando na roda": reflexões sobre práticas avaliativas na universidade. Revista Internacional de Educação Superior, 4(3), 664-684. https://doi.org/10.20396/riesup.v4i3.8652413

Silva, L. R. da (2009). A relação professor-aluno no ensino superior. [Monografia de Especialização em Docência do Ensino Superior, Universidade Cândido Mendes, Brasília]. http://www.avm.edu.br/docpdf/monografias_publicadas/posdistancia/43620.pdf

Silva, N. L., \& Mendes, O. M. (2017). Avaliação formativa no ensino superior: avanços e contradições. Revista da Avaliação da Educaşão Superior, 22(1), 271-297. https://doi.org/10.1590/s141440772017000100014

Soares, A. B., Gomes, G., Maia, F. de A., Gomes, C. A. O., \& Monteiro, M. C. (2016). Relações interpessoais na universidade: o que pensam estudantes da graduação em psicologia?. Estudos Interdisciplinares em Psicologia, 7(1), 56-76. http://pepsic.bvsalud.org/scielo.php?script=sci_arttext\&pid=S223664072016000100005\&lng $=$ pt\&tlng $=$ pt

Souza, C. F. dos S. (2016). Relação afetiva entre professores e estudantes do ensino superior: sentidos, desafios e possibilidades. [Dissertação de Mestrado em Educação, Universidade Estadual de Feira de Santana]. http://tede2.uefs.br:8080/handle/tede/383

Souza, C. F. dos S., \& Ribeiro, M. L. (2017). Representações de práticas docentes que afetam negativamente estudantes de Engenharia Civil. Plures Humanidades, 18(1), 158-176. http://seer.mouralacerda.edu.br/index.php/plures/article/download/284/236

Viana, C. M. Q. Q., \& Silva, E. F. da (2017). A aula na educação superior: desafios e perspectivas na atualidade. Revista de Administração Educacional, $\quad 1(1), \quad$ 67-80. https://periodicos.ufpe.br/revistas/ADED/article/view/23121/18844 


\section{Sobre os Autores}

\section{MARINALVA LOPES RIBEIRO}

(D) ORCID: https://orcid.org/0000-0002-9197-1341

Pós-Doutorado em Educação, Professora Permanente do Programa de Pós-Graduação em Educação Universidade Estadual de Feira De Santana (UEFS); Pesquisadora do Núcleo de Estudos e Pesquisas sobre Pedagogia Universitária (NEPPU) - marinalva_biodanza@hotmail.com.

\section{JEIZIANE DA SILVA OLIVEIRA}

(D) ORCID: https://orcid.org/0000-0002-3410-2094

Graduanda em Pedagogia - Universidade Estadual de Feira de Santana (UEFS); Bolsista de Iniciação Científica CNPQ - jeizi.oliveira@hotmail.com.

\section{EVÓDIO MAURÍCIO OLIVEIRA RAMOS}

(D) ORCID: https://orcid.org/0000-0002-1046-7136

Doutor em Educação, Professor Permanente do Programa de Pós-Graduação em Educação Universidade Estadual de Feira de Santana (UEFS); Pesquisador do Núcleo de Estudos e Pesquisas sobre Pedagogia Universitária (NEPPU) - emoramos@uefs.br.

Enviado: 22 ago. 2020

Aprovado: 03 mar. 2021. 